\title{
Paramecium tetraurelia basal body unit isolation for Cryo-electron tomography studies
}

\author{
S Trépout ${ }^{1,2}$, M Lemullois ${ }^{3}$, P Guichard ${ }^{4}$, F Koll ${ }^{3}$, A Aubusson-Fleury ${ }^{3}$, J Beisson ${ }^{3}$, J Cohen ${ }^{3}$, S Marco ${ }^{1,2}$, AM Tassin $^{3 *}$ \\ From Cilia 2014 - Second International Conference \\ Paris, France. 18-21 November 2014
}

\section{Objective}

The Transition Zone (TZ) is defined as the most proximal region of the cilium overlapping with the most distal region of the basal body. This zone has been shown to play a crucial role in cilia biology since it is considered as the site of sorting of proteins that transit to cilia. Protein complexes housed at this zone are found mutated in MKS/NPHP ciliopathies. Although its organization varies from organism to organism, the TZ molecular composition and function are highly conserved. In Paramecium, the TZ is well structured with three distinct plates defined as the terminal, the intermediate and the axosomal plates. In this model, structural and molecular changes of the $\mathrm{TZ}$ are observed as anchored basal bodies become ciliated. Therefore, Paramecium appears to be a pertinent model to study the $\mathrm{TZ}$ at an ultrastructural level in correlation with its functionality.

\section{Methods}

To reach this goal, we have developed a technique to isolate Paramecium basal body cortex units. These units fit the cryo-electron tomography requirements allowing us their visualisation in native conditions at nanometric resolution.

\section{Results}

First cryo-tomograms obtained on these Paramecium units allow the observation of well-preserved basal bodies revealing the $\mathrm{TZ}$ with its three recognisable plates and the Y-links as well as at the proximal part of the basal body, the cartwheel and the radial spokes.
${ }^{3}$ UPR 3404-Centre de Génétique Moléculaire, Gif sur Yvette, CNRS, Gif Sur Yvette, Paris, France

Full list of author information is available at the end of the article

\section{Conclusion}

Thus, studies of the consequences of $\mathrm{TZ}$ protein depletion at high resolution are now achievable by combining new isolation protocols and cryo-electron tomography.

\section{Authors' details}

${ }^{1}$ Campus Universitaire, Bat 112, INSERM U759, Orsay Cedex, France. ${ }^{2}$ Centre de Recherche, Institut Curie, Orsay F-91405, France. ${ }^{3}$ UPR 3404-Centre de Génétique Moléculaire, Gif sur Yvette, CNRS, Gif Sur Yvette, Paris, France. ${ }^{4}$ School of Life Sciences, Swiss Federal Institute of Technology (EPFL), Swiss Institute for Experimental Cancer Research (ISREC), Lausanne, Switzerland.

Published: 13 July 2015

\section{doi:10.1186/2046-2530-4-S1-P68}

Cite this article as: Trépout et al:: Paramecium tetraurelia basal body unit isolation for Cryo-electron tomography studies. Cilia 2015

4(Suppl 1):P68.
Submit your next manuscript to BioMed Central and take full advantage of:

- Convenient online submission

- Thorough peer review

- No space constraints or color figure charges

- Immediate publication on acceptance

- Inclusion in PubMed, CAS, Scopus and Google Scholar

- Research which is freely available for redistribution
() Biomed Central 